\title{
Knowledge and Attitude of Newly Diagnosed Breast Cancer Patients and Their Accompanying Attendants About Multimodality Treatment for Breast Cancer
}

Nahan Siddique Ruby ${ }^{1}$, Chellappa Vijayakumar ${ }^{1}$, Sudharsanan Sundaramurthi ${ }^{1}$, Sathasivam Sureshkumar 1 , Uday Kumbhar $^{1}$, Gopal Balasubramanian ${ }^{1}$

1. Surgery, Jawaharlal Institute of Postgraduate Medical Education and Research (JIPMER), Puducherry, IND

Corresponding author: Chellappa Vijayakumar, vijaymmc01@gmail.com

\section{Abstract}

\section{Introduction}

This study was done to estimate the level of knowledge and attitude about the multimodality treatment (MMT) of breast cancer among the newly diagnosed breast cancer patients and accompanying attendants. Apart from the lack of knowledge, it is equally important to consider their accompanying attendant's knowledge, which changes the patient's attitude.

\section{Methodology}

This was a cross-sectional analytic study, including all newly diagnosed breast cancer patients of age above 18 years. The initial questionnaire one (Q1) was about their overall knowledge of carcinoma breast treatment options. Subsequent questionnaire two (Q2) were asked about MMT for breast cancer at eliciting their attitudes about MMT. After explaining about MMT for breast cancer, they were asked to indicate if they had a positive/negative attitude about MMT by questionnaire three (Q3).

\section{Results}

A total of 84 patients was included in the study. The results indicate a significant association between the relation of the attendant to the patient and their level of knowledge of MMT ( $<<0.001)$. Approximately $62 \%$ of study patients preferred a passive role in making their treatment decisions of MMT, with nearly $26.2 \%$ preferring their treating doctor to make all decisions while $36.7 \%$ preferred decisions by accompanying attendants. None of the patients had a negative attitude about MMT.

\section{Conclusion}

Received 04/09/2020

Review began 04/22/2020 Review ended 04/22/2020 Published 05/01/2020

\section{(c) Copyright 2020}

Ruby et al. This is an open access article distributed under the terms of the Creative Commons Attribution License CC-BY 4.0., which permits unrestricted use, distribution, and reproduction in any medium, provided the original author and source are credited.
The treating surgeon should analyse the patient's knowledge of MMT and their attitude toward involving their accompanying attendants in making MMT decisions. It is necessary to administer adequate knowledge regarding MMT and discuss the various treatment options for breast cancer with the ailing patient, along with the accompanying attendants.

Categories: General Surgery, Oncology, Public Health

Keywords: awareness, knowledge, attitude, multi-modality treatment, breast cancer

\section{Introduction}

Providing adequate knowledge to patients about breast cancer helps them cope with cancer treatment [1]. The accompanying attendant role is important among the other key participants for a patient with breast cancer [2]. Knowledge and attitude towards multimodality treatment (MMT) also differ among different patient populations [3-4]. Family participation in decision making and communication is essential for cancer patients especially in developing countries like India [5]. The solution to active participation in breast cancer management lies in providing adequate knowledge about MMT of breast cancer. Apart from a lack of knowledge, it is equally important to consider their accompanying attendant's knowledge, which changes patient's attitudes [6]. This study was done to estimate the level of knowledge and attitude about MMT for breast cancer among the newly diagnosed breast cancer patients and their accompanying attendants.

This article was first presented for an undergraduate research award (Golden Jubilee Short-Term Research Award to undergraduate students-GJSTRAUS) at the Fifth Annual Research Day 2020, Jawaharlal Institute of Postgraduate Medical Education and Research (JIPMER), Pondicherry, India, January 10, 2020

(https://www.jipmer.edu.in/sites/default/files/Souvenir-

5th\%20JIPMER\%20Research\%20Day\%20Jan\%202020.pdf). 


\section{Materials And Methods}

This cross-sectional analytical study was done at a tertiary care centre in South India for a period of six months (March 2019 to August 2019). Approval was taken from the institute's ethics committee (Human Studies). Study patients were all newly diagnosed breast cancer patients of age above 18 years attending the outpatient department (OPD). The study excluded breast cancer patients presenting to the emergency department with complications, terminally ill breast cancer patients, and patients partially treated elsewhere. Patients and their accompanying attendants were interviewed with a standardized questionnaire after obtaining informed consent. The questionnaire used was validated in the Indian set up [7].

The patients and accompanying attendants were asked to select one of the responses from A to F statements as mentioned in this study results. The first two statements (A and B) and the third statement (C) were considered an active role and a collaborative role in the attitude of their MMT, respectively. Similarly, the next two statements (D and $\mathrm{E}$ ) and the final statement $(\mathrm{F})$ were considered a passive role and negative role in the attitude of their MMT respectively. Data regarding the patient's and the accompanying attendant's knowledge of MMT, educational status, income, occupation, marital status, and residence were obtained by interviewing them. Data regarding diagnosis (stage of breast cancer), treatment (MMT) status, time since diagnosis, and comorbidities were obtained from case records.

\section{Statistical analysis}

Categorical variables were expressed as proportions in the analysis. The association with other factors was analysed using the chi-square test. Multivariate logistic regression could not be done because of the small sample size. A p-value of $<0.05$ was considered statistically significant. The analysis was done by using statistical software IBM SPSS version 21.0 (IBM Corp., Armonk, NY).

\section{Results}

A total of 42 patients gave consent to participate in this study. The mean age of the study patients was 45.7 years. The majority of breast cancer patients $(n=26: 61.9 \%)$ were from urban areas. Of all the study patients, only two (4.76\%) were graduates. All the patients were married. Accompanying attendants of all the 42 patients gave consent to participate in this study. The mean age of the accompanying attendants was 37.5 years. The majority of the accompanying attendants $(n=31 ; 73.8 \%)$ were from urban areas. Of all the accompanying attendants, 10 (23.8\%) were graduates. The majority of the accompanying attendants $(\mathrm{n}=32 ; 76.19 \%)$ were directly related to the patient, either husband or son/daughter.

Among the study patients, 29 (69.05\%) had partial knowledge of the treatment of breast cancer and the specific meaning of MMT but they wanted further details and individual aspects of MMT. The proportion of patients who partially knew, but would like to know, about the week-by-week progress of MMT, chances of a cure if not treated by MMT, components of MMT and side effects of MMT were $64.3 \%, 76.2 \%, 66.7 \%$, and $61.9 \%$, respectively. The proportion of patients who want to know exactly how MMT works to treat breast cancer was $76.2 \%$ in this study. Among the accompanying attendants, 30 (71.5\%) and 33 (78.6) partially knew about the treatment of breast cancer and the specific meaning of MMT, but they wanted further details and individual aspects of MMT. The proportion of accompanying attendants who partially knew but would like to know about the week-by-week progress of MMT, chances of a cure if not treated by MMT, components of MMT, and side effects of MMT were $81 \%, 83.3 \%, 73.8 \%$, and $73.8 \%$, respectively. The proportion of accompanying attendants who want to know exactly know how MMT works to treat breast cancer was $78.8 \%$ in this study.

On studying the knowledge level, an average level (7-9) of knowledge of MMT was found in 23 (54.8\%) patients and 29 (69\%) accompanying attendants. A very good level (>13) of knowledge was studied in three $(7.1 \%)$ patients and in one (2.4\%) attendant (Table 1$)$. 


\section{Cureus}

\begin{tabular}{|c|c|c|}
\hline Level of Knowledge & Patients [N (\%)] & Accompanying attendants [N (\%)] \\
\hline Very good (>13) & $3(7.1)$ & $1(2.4)$ \\
\hline Good (10 -12) & $3(7.1)$ & $3(7.1)$ \\
\hline Average (7-9) & $23(54.8)$ & $29(69)$ \\
\hline Poor (4-6) & $5(11.9)$ & $3(7.1)$ \\
\hline Very poor $(<3)$ & $8(19)$ & $6(14.3)$ \\
\hline
\end{tabular}

TABLE 1: Level of knowledge of MMT of the patients and accompanying attendants

MMT: multimodality treatment

Regarding participation in treatment after knowing about MMT by making individual/combined decisions, 26 patients $(61.9 \%)$ preferred a passive role, nine patients $(21.4 \%)$ preferred an active role, and seven (16.7\%) preferred a collaborative role. None of the patients had a negative attitude towards MMT (Table 2).

\section{Statement}

A. I prefer to make the final selection about which treatment I will receive

B. I prefer to make the final selection of my treatment after seriously considering my doctor's opinion

C. I prefer that my doctor and I share responsibility for deciding which treatment is best for me

D. I prefer that my doctor make the final decision about which treatment, but seriously considers my opinion

E. I prefer to leave all decisions regarding treatment to my accompanying attendants

F. I don't want to continue any type of treatment in future
Preference for MMT decision,

[N (\%)]

\section{$6(14.3)$}

Active role, 9 (21.4)

$3(7.1)$

7 (16.7) Collaborative role, 7 (16.7)

\section{1}

(26.2)

Passive role, 26 (61.9)

15

(35.7)

$0 \quad$ Negative attitude, 0

TABLE 2: Attitude of patients to participate in treatment after knowing about MMT

A, B, C, D, E, F: different patient statements; MMT: multimodality treatment

Regarding participation in treatment after knowing about MMT by making individual/combined decisions, 23 accompanying attendants (54.8\%) preferred an active role, 13 accompanying attendants (31\%) preferred a collaborative role, and six (14.3\%) preferred a passive role. None of the accompanying attendants had a negative attitude towards MMT (Table 3). 


\section{Cureus}

Statement

N (\%)

for MMT decision,

[N (\%)]

A. I prefer to make the final selection about which treatment she will receive

11

(28.6)

Active role, 23 (54.8)

B. I prefer to make the final selection of her treatment after seriously considering my some more relative's opinion

C. I prefer that another relatives and I share responsibility for deciding which treatment is best for her

D. I prefer that another relative's make the final decision about which treatment, but seriously considers my opinion

E. I prefer to leave all decisions regarding treatment to another relative

F. I don't want to continue any type of treatment in future
12(26.2)

13 (31) Collaborative role, 13 (31)

5 (11.9)

0 (0) Negative attitude, $0(0)$

TABLE 3: Attitude of accompanying attendants to participate in treatment after knowing about MMT

A, B, C, D, E, F: different accompanying attendant statements; MMT: multimodality treatment

There was no significant association between secondary factors like age, residence, education, income, marital status, performance status, time since diagnosis, and treatment plan with the level of knowledge about MMT. There was a significant association between close relatives like husband/son/daughter and the average level of knowledge $(\mathrm{N}=23 ; 71.87 \% ; \mathrm{p}=0.001)$. Other than this, there was no significant association between the secondary factors of attendants like age, residence, education, income, marital status, performance status, time since diagnosis, treatment plan, and level of knowledge about MMT.

The patient attitude scale also did not show any significant association with demographic variables, stage of the disease, treatment plan, performance status and time since diagnosis. Patients who were awaiting neoadjuvant treatment and palliative care preferred a collaborative decision with their accompanying attendants when compared to those who were to undergo upfront surgery and those who were in the early breast cancer stage (Table 4). 


\section{Cureus}

\begin{tabular}{|c|c|c|c|c|c|c|}
\hline \multicolumn{2}{|c|}{ Parameter [N(\%)] } & A \& B (Active role) & C (Shared role) & D \& E (Passive role) & F (Negative Role) & p-value \\
\hline \multirow{2}{*}{ Age } & $<40$ & $3(42.8)$ & 2 (28.6) & $2(28.6)$ & 0 & \multirow{2}{*}{0.134} \\
\hline & $>40$ & $6(17.1)$ & $5(14.3)$ & $24(68.6)$ & 0 & \\
\hline \multirow{2}{*}{ Residence } & Urban & $3(18.7)$ & $4(25)$ & $9(56.2)$ & 0 & \multirow{2}{*}{0.523} \\
\hline & Rural & $6(23)$ & $3(11.5)$ & $17(65.4)$ & 0 & \\
\hline \multirow{4}{*}{ Education } & Primary School & 0 & $2(33.3)$ & $4(66.7)$ & 0 & \multirow{4}{*}{0.266} \\
\hline & High School & $5(27.8)$ & $3(16.7)$ & $10(55.5)$ & 0 & \\
\hline & College & $1(50)$ & $1(50)$ & 0 & 0 & \\
\hline & None & $3(18.7)$ & $1(6.25)$ & $12(75)$ & 0 & \\
\hline \multirow{2}{*}{ Income } & $<2000$ & $4(23.5)$ & $0(0)$ & $13(76.5)$ & 0 & \multirow{2}{*}{0.055} \\
\hline & $>2000$ & $5(20)$ & $7(28)$ & $13(25)$ & 0 & \\
\hline \multirow{2}{*}{ Marital status } & Married & $9(21.4)$ & 7(16.7) & $26(61.9)$ & 0 & \multirow{2}{*}{-} \\
\hline & Unmarried & 0 & 0 & 0 & 0 & \\
\hline
\end{tabular}

TABLE 4: Association of the demographic profile and attitude of the patients with MMT decisions

A, B, C, D, E, F: different patient statements; MMT: multimodality treatment

The accompanying attendant's scale also did not show any significant association with demographic variables, stage of the disease, income, relation with patient, and treatment plan. Attendants of patients who were awaiting neo-adjuvant treatment and palliative care preferred a collaborative decision with their treating surgeon when compared to those who were undergoing upfront surgery and those who were in the early breast cancer stage (Table 5). 


\begin{tabular}{|c|c|c|c|c|c|c|}
\hline \multicolumn{2}{|c|}{ Parameter [N (\%)] } & A \& B (Active role) & C (Shared role) & D \& E (Passive role) & F (Negative Role) & p-value \\
\hline \multirow{2}{*}{ Age } & $<40$ & $15(62.5)$ & $6(25)$ & $3(12.5)$ & 0 & \multirow{2}{*}{0.502} \\
\hline & $>40$ & $8(44.4)$ & $7(38.8)$ & $3(16.7)$ & 0 & \\
\hline \multirow{2}{*}{ Residence } & Urban & $6(54.5)$ & $5(45.4)$ & 0 & 0 & \multirow{2}{*}{0.208} \\
\hline & Rural & $17(68)$ & $8(32)$ & 0 & 0 & \\
\hline \multirow{4}{*}{ Education } & Primary School & $2(66.7)$ & $1(33.3)$ & 0 & 0 & \multirow{4}{*}{0.604} \\
\hline & High School & $15(55.6)$ & $9(33.3)$ & $3(11.1)$ & 0 & \\
\hline & College & $6(60)$ & $2(20)$ & $2(20)$ & 0 & \\
\hline & None & 0 & $1(50)$ & $1(50)$ & 0 & \\
\hline \multirow{5}{*}{ Relationship } & Husband & $19(59.4)$ & $8(25)$ & $5(15.6)$ & 0 & \multirow{5}{*}{0.653} \\
\hline & Mother & $1(33.3)$ & $2(66.7)$ & 0 & 0 & \\
\hline & Sister & $2(40)$ & $2(40)$ & $1(20)$ & 0 & \\
\hline & Friend & 0 & $1(100)$ & 0 & 0 & \\
\hline & Relatives & $1(100)$ & 0 & 0 & 0 & \\
\hline
\end{tabular}

TABLE 5: Association of the demographic profile and attitude of the accompanying attendant with MMT decisions

A, B, C, D, E, F: different accompanying attendant statements; MMT: multimodality treatment

\section{Discussion}

The patient's demographic parameters did not affect the level of knowledge about MMT. Similarly, the accompanying attendant's demographic parameters also did not affect their MMT knowledge. Many studies concluded that most of the young, educated patients wanted to know about MMT with a positive attitude towards their treatment [8-9]. Although the majority of this study's patients and the accompanying attendants had a lower level of education, they wanted to know about MMT.

In this study, approximately $16.6 \%$ preferred a collaborative role in their MMT. This is in contrast to the western studies where more patients preferred a collaborative role in their treatment [9-10]. Singh et al. in their study found that more than $50 \%$ of patients preferred a collaborative role with their treating surgeons [4]. Similarly, Schaede et al. and Breura et al. in their studies showed that $63 \%$ of patients preferred a collaborative role while $20 \%$ preferred an active role and only $17 \%$ preferred a passive role in their treatment decisions [10-11]. In this study, similar results were seen with regards to the preference for the active role while there was an abrupt contrast in the number of patients preferring a collaborative or passive role. The majority of Indian patients prefer a passive role in their treatment due to a lower level of education and their preference to give importance to their health than their personal appearance [7,11]. Gilani et al. and Kraetschmer et al. in their studies found that patients and accompanying attendants prefer an active role when the trust levels are less with the treating surgeons [12-13]. Sankar et al. found that Indian patients and their accompanying attendants are used to a paternalistic approach when the trust levels are higher with their treating surgeon [7]. This may be the reason why the majority of this study's patients played a passive role in MMT.

The stage of breast cancer did not have a significant role in the patient's attitude. Similarly, the attitude of accompanying attendants did not have a significant association with baseline demographic factors. A collaborative role with the accompanying attendants has been shown to be associated with improved outcomes in breast cancer patients. Sankar et al. found that involving accompanying attendants increased patient satisfaction in their treatment pathway [7]. Few studies found that an active role controlled by family members was more common among Asians [7,13]. It is often seen from one responsible accompanying attendant who takes most of the health-related decisions in their family [7]. This may be the reason why a majority of this study patients preferred a collaborative role with their accompanying attendants. Many studies have found that Indian patients have the tendency to change their attitudes frequently $[7,14]$. Providing appropriate knowledge about MMT to accompanying attendants can facilitate their active participation. Hence, the accompanying attendant's involvement has been shown to be associated with improved outcomes in breast cancer patients. The strength of this study was that there was no data 


\section{Limitations}

This study was conducted in a single tertiary care institute in South India with a small sample size. Since most of the study patients were from poor socio-economic backgrounds, study results may not be represented by the other parts of India. Further prospective analytic studies with a large sample size are required to assess the knowledge and attitude among patients and accompanying attendants representing all socioeconomic levels.

\section{Conclusions}

The majority of patients and their accompanying attendants want to know more about the MMT of breast cancer. Although patients have a desire to know more about MMT, their attitude towards MMT for breast cancer was more passive. The majority of patients with a passive role in treatment wanted their accompanying attendants to lead the active role in their treatment. Hence, providing appropriate knowledge about MMT to accompanying attendants can facilitate their better involvement, which in a country like India, with high family values, can influence the outcome of breast cancer patients.

\section{Additional Information \\ Disclosures}

Human subjects: Consent was obtained by all participants in this study. JIPMER Undergraduate Research Monitoring Committee (UGRMC) issued approval JIP/UGRMC/GJ-STRAUS/2019/22. This is to certify that the Project entitled: Knowledge and attitude of newly diagnosed breast cancer patients and their accompanying attendants about multimodality treatment of breast cancer - A cross-sectional analytic study (Project Number JIP/UGRMC/GJ-STRAUS/2019/22) is a bonafide work done by Ruby Nahan Siddique (Student's name) of VII semester MBBS under our guidance and supervision in the Department of Surgery, Jawaharlal Institute of Postgraduate Medical Education and Research(JIPMER), Puducherry, under the GJ-STRAUS20182019 program of UGRMC. Animal subjects: All authors have confirmed that this study did not involve animal subjects or tissue. Conflicts of interest: In compliance with the ICMJE uniform disclosure form, all authors declare the following: Payment/services info: All authors have declared that no financial support was received from any organization for the submitted work. Financial relationships: All authors have declared that they have no financial relationships at present or within the previous three years with any organizations that might have an interest in the submitted work. Other relationships: All authors have declared that there are no other relationships or activities that could appear to have influenced the submitted work.

\section{References}

1. Kumar S, Imam AM, Manzoor NF, Masood N: Knowledge, attitude and preventive practices for breast cancer among health care professionals at Aga Khan Hospital Karachi. J Pak Med Assoc. 2009, 59:474-478.

2. Wei S, Chen F, Chen H, et al.: Patients' and family members' decision-making and information disclosure preferences in a single-center survey in China: a pilot study. Am J Hosp Palliat Care. 2016, 33:733-741. 10.1177\%2F1049909115588302

3. Muthu Kumar D, Symonds RP, Sundar S, Ibrahim K, Savelyich BSP, Miller E: Information needs of Asian and White British cancer patients and their families in Leicestershire: a cross- sectional survey. Br J Cancer. 2004, 90:1474-1478. 10.1038/sj.bjc.6601774

4. Singh JA, Sloan JA, Atherton PJ, et al.: Preferred roles in treatment decision making among patients with cancer: a pooled analysis of studies using the Control Preferences Scale. Am J Manag Care. 2010, 16:688696.

5. Chaturvedi SK, Loiselle CG, Chandra PS: Communication with relatives and collusion in palliative care: a cross-cultural perspective. Indian J Palliat Care. 2009, 15:2-9. 10.4103/0973-1075.53485

6. Rutten LJ, Arora NK, Bakos AD, Aziz N, Rowland J: Information needs and sources of information among cancer patients: a systematic review of research (1980-2003). Patient Educ Couns. 2005, 57:250-261. 10.1016/j.pec.2004.06.006

7. Sankar SD, Dhanapal B, Shankar G, Krishnaraj B, Karra S, Natesan V: Desire for information and preference for participation in treatment decisions in patients with cancer presenting to the department of general surgery in a tertiary care hospital in India. J Glob Oncol. 2018, 4:1-10. 10.1200/JGO.17.00144

8. Laxmi S, Khan JA: Does the cancer patient want to know? Results from a study in an Indian tertiary cancer center. South Asian J Cancer. 2013, 2:57-61. 10.4103/2278-330X.110487

9. Kehl KL, Landrum MB, Arora NK, et al.: Association of actual and preferred decision roles with patientreported quality of care. Shared decision making in cancer care. JAMA Oncol. 2015, 1:50-58. 10.1001/jamaoncol.2014.112

10. Bruera E, Sweeney C, Calder K, Palmer L, Benisch-Tolley S: Patient preferences versus physician perceptions of treatment decisions in cancer care. J Clin Oncol. 2001, 19:2883-2885. 10.1200/JCO.2001.19.11.2883

11. Schaede U, Mahlich J, Nakayama M, et al.: Shared decision-making in patients with prostate cancer in Japan: patient preferences versus physician perceptions. J Glob Oncol. 2018, 4:1-9. 10.1200/JGO.2016.008045

12. Gilani SI, Khurram M, Mazhar T, et al.: Knowledge, attitude and practice of a Pakistani female cohort towards breast cancer. J Pak Med Assoc. 2010, 60:205-208. 


\section{Cureus}

13. Kraetschmer N, Sharpe N, Urowitz S, Deber RB: How does trust affect patient preferences for participation in decision-making?. Health Expect. 2004, 7:317-326. 10.1111/j.1369-7625.2004.00296.x

14. Hack TF, Degner LF, Watson P, Sinha L: Do patients benefit from participating in medical decision making? Longitudinal follow-up of women with breast cancer. Psychooncology. 2006, 15:9-19. 10.1002/pon.907 